\title{
The Formation and Development of Chinese EFL Learners' English Mental Lexicon
}

\author{
Zhongxin Dai ${ }^{1} \&$ Kemin Wang ${ }^{1}$ \\ ${ }^{1}$ College of Foreign Languages, North China Electric Power University, Beijing, China \\ Correspondence: College of Foreign Languages, North China Electric Power University, No 2, Beinong Road, \\ Huilongguan, Changping District, Beijing 102206, China. E-mail: zhongxindai@126.com
}

Received: January 1, 2013 Accepted: January 12, 2013 Online Published: February 1, 2013

doi:10.5539/elt.v6n3p51 URL: http://dx.doi.org/10.5539/elt.v6n3p51

\begin{abstract}
This paper investigated some dominant features and influential factors in the formation and developmental process of the English mental lexicon of Chinese EFL learners. Data were collected by means of word tests. The result of the data analysis shows: (1) Chinese EFL learners acquire very little of the overall word knowledge; and (2) aspects of the multifaceted word knowledge increase with the improvement of their language proficiency.
\end{abstract}

Keywords: Chinese EFL learner, mental lexicon, formation, development

\section{Introduction}

It is now universally acknowledged that vocabulary acquisition is of critical importance to second language (L2) learners, and a solid vocabulary is necessary in every stage of second language learning (McCarthy, 1990; Laufer, 2002). Although the importance of vocabulary acquisition in L2 learning has been widely recognized, efficient and effective ways of vocabulary learning and teaching have never been found. Just as Ma (2002) observed, teachers and students alike have spent much time and effort teaching and learning English vocabulary, but the result is far from satisfactory. The problem of vocabulary acquisition still remains unsolved.

It is obvious that knowing a word means more than just knowing its form. According to Nation $(1990,2001)$, to know a word, besides the phonological and morphological form, one must also know the meaning and the use of the word. Then, which aspects of an English word has a Chinese L2 learner already acquired? How are these aspects stored in their mental lexicon? How does their mental lexicon develop as their English proficiency improves? What are the factors that may influence the formation and development of Chinese L2 learners' English mental lexicon? There are numerous questions like these concerning the mental lexicon of Chinese L2 learners.

Research on the mental lexicon of Chinese L2 learners has been concerned with the nature of the L2 mental lexicon, the difference between the nature of L1 and L2 mental lexicon, and the developmental process of the L2 mental lexicon, but the focus has been mainly on word association (e.g. Zhang, 2004; Zhang, 2006; Zhang, 2009). Word association is only one aspect of the L2 mental lexicon, i.e. the phonological or semantic nature of the L2 mental lexicon. The present study attempts to make a comprehensive exploration into Chinese L2 learners' English mental lexicon, addressing such questions as what aspects of a word are stored in the English mental lexicon of Chinese L2 learners, why it is these aspects, not other aspects that are stored, and how these aspects develop or grow as the learners' knowledge of English increases.

\section{Research Design}

According to Navracsics (2007, p. 17), "the mental lexicon is a kind of internal dictionary that contains not only the 'entries' for each word a speaker knows but also all the linguistic information about the word: its semantic content, syntactic properties, phonological shape, and so on." Richards (1976) holds that knowing a word involves knowing its frequency, register, syntax, derivation, association, semantic feature and polysemy. Faerch and Kasper (1986) point out that to know a word is to get familiar with its potential meanings, understand its collocation with other words and get to know its relations with other words. Laufer (1990) believes that, knowledge of a word involves not only the knowledge of its meaning, but also knowledge of its spelling and pronunciation, part of speech, frequency, polysemy, connotation, usage and collocation. Nation (1990) develops Richards' eight categories by adding a productive and receptive distinction. According to him, the main 
categories involved in knowing a word are: form (spoken and written), position (grammatical patterns and collocations), function (frequency and appropriateness) and meaning (concepts and associations), and each of these categories is described in terms of receptive and productive aspects. Nation (2001) reclassifies the information in mental lexicon into three main categories: form, meaning and use. Singleton (2000) maintains that knowing a word involves knowing its sound and written form, what it means, how it behaves morphologically, how it behaves syntactically, how it keeps company with other words, how its interpretation shifts in different contexts, and the social contexts in which it would and would not be likely to occur.

In this paper, we retain Singleton's classification and study the mental lexicon of Chinese L2 learners from its form (phonological or written), meaning, morphology, syntax, collocation, contexts, and word use in social contexts. We believe that the information of a word stored in the mental lexicon is related to the knowledge obtained while the word is being learned and used. Thus the working mechanisms should be approached "on the spot" where the word is being learned or used. In order to set the scene for the demonstration of the learner's mental lexicon, we designed word knowledge tests. We want to find out what aspects of the word knowledge, and to what degree, Chinese English learners have stored in their English mental lexicon, and how they acquire and develop the knowledge. Some interviews were also conducted so as to explore in-depth lexical knowledge of the learners. All of the introductions and directions to the questions are expressed in Chinese to make sure that the learners understand the questions better and therefore the data obtained is more authentic and objective.

The test involves 400 students randomly chosen from North China Electric Power University and China University of Petroleum (Beijing Campus). The history and background of their English learning are quite identical. All of them, aged between 17 to 23, have learned English as a foreign language (EFL) for about 7 to 9 years with Chinese as their native language, and never lived in an English speaking country. As the freshmen have just begun their English learning in universities, they are considered in the present research as the low-proficiency group. In these two universities, English teaching lasts for two years, which means juniors have completed the compulsory English courses. Therefore, the juniors and seniors are regarded as the high-proficiency group. The sophomores have learnt English for one year in the university and will continue learning English for another year. They are supposed to be more proficient in English than the freshmen, but less proficient than the juniors and seniors. They are the intermediate group.

400 copies were handed out with 328 back. Among the 328 copies back, 20 copies were left out because some items were not finished or not completed as required. Therefore, only 308 copied were left valid for the present research. Among these 308 copies, 118 copies were performed by the freshmen, 100 by the sophomores and 90 by the juniors and seniors.

\section{Data Analysis and Discussion}

The word knowledge test is designed to explore the eight aspects of the word knowledge in the English mental lexicon of Chinese EFL learners. There are altogether eleven questions.

Question 1 concerns word form. The participants are asked to choose the correct phonetic symbols for the underlined words or provide correct spellings according to the phonetic transcription given. For instance, the participants are asked to supply the word form according to the sound transcription of the word in the sentence "She was uncertain ___ (/'weðə/) to stay or leave." All the test words are randomly chosen from High School English Curriculum Standards (Glossary).

The purpose of this question is to examine the store of phonological and written forms in Chinese EFL learners' English mental lexicon. The result of the collected data shows that students at different developmental stages produce a similar proportion of responses in the word form test. More than 55\% students still have difficulty in distinguishing between similar word forms (both phonological forms and written forms), about $38 \%$ students can recognize and produce most word forms correctly and only a small proportion of students can perform well in all the three required tasks: recognizing different word forms, distinguishing between different words forms and finally providing correct word forms.

What is also suggested in the data is the developmental process of word forms in Chinese EFL learners' mental lexicon. As students' language proficiency levels increase, the proportion of correct responses they produce also increases. Among the freshmen and sophomores, no more than $40 \%$ students produce more than three correct responses; however, the percentage rises to more than $44 \%$ for the juniors and seniors.

In Question 2, the participants are asked to identify the meaning of the English word "uncle". There are four choices: A. uncle $=$ shushu (father's younger brother), B. uncle $=$ shushu, bofu (father's brother, both younger and elder), C. uncle = shushu, bofu, jiufu (father's brother or mother's brother), D. uncle = shushu, bofu, jiufu, 
gufu, yifu (father's brother, mother's brother, the husband of father's sister, or the husband of mother's sister), and E. uncle = fumu de xiongdi, fumu jiemei de zhangfu (the brother of one's father or mother; the husband of one's aunt).

The purpose of this question is to explore word meaning or the lexical concept of a word in Chinese EFL learners' English mental lexicon. The result of the collected data shows that the meaning of uncle stored in Chinese EFL learners' English mental lexicon is incomplete. There are a large number of students who have not developed the complete concept of the English word uncle even though they have learnt the word for many years. For some students, the meaning of uncle stored in their mental lexicon is the Chinese equivalent shushu (father's younger brother), though uncle covers a much wider concept than shushu. Only $28 \%$ of the freshmen and sophomores have formed a complete concept of the word uncle. The result of the data also indicates the development of English word meaning in Chinese EFL learners' mental lexicon. Juniors and seniors have more meaning elements than freshmen and sophomores.

When they are asked to identify the meaning senses of the English word "beautiful" in Question 3, more than $50 \%$ of the participants demonstrate incomplete mastery of the word concept. For some students (about $12 \%$ ), beautiful is just related to the visual sense, and the meaning stored in their mental lexicon is the Chinese equivalent meili de (that can give pleasure to the visual sense) though beautiful can be used to describe anything that can give pleasure to any of the five senses. We can also find the development of word meaning in Chinese EFL learners' English mental lexicon. Juniors and seniors have more complete meaning of the word than freshmen and sophomores.

Question 4 is rendered as follows: "The English word "riddle" is a word you learnt at middle school. If you know the word, please write down two Chinese verbs that usually go together with the Chinese translation equivalent of this word. Once you have finished this, please translate the Chinese phrases into English." The purpose of this question is to detect the state of lexical collocation in Chinese EFL learners' English mental lexicon. Knowing a word involves knowing about the company it keeps. This question is paired with Question 5, where the English word is "beard".

In both cases, there are a large number of students who do not know the meaning of this word. And among those who know the meaning of the word, only a small percentage of students can produce one or two English collocations. For instance, in the case of "beard", only $11 \%$ of the freshmen, $17 \%$ of the sophomores and $21 \%$ of the juniors and seniors are capable of producing English collocations of the word. Further examination of the data reveals the development of word collocation in Chinese EFL learners' English mental lexicon. Compared with the freshmen and sophomores, there are fewer juniors and seniors who do not know the meaning of the word. As the language learners' proficiency increases, the percentage of students who can produce English collocations also increases. Compared with the increase of the vocabulary size and the number of word meanings stored in their mental lexicon, word collocations in the mental lexicon increase at a relatively slow pace.

Question 6 is to explore the usage patterns of the English word "save". It is intended to discover the knowledge of word syntax in Chinese EFL learners' English mental lexicon. Knowing a word involves knowing how it behaves syntactically. As for the word "save", the researchers expect the students to supply such structures as "save somebody", "save something", "save somebody from something", "save something for somebody", and the like. The collected data indicate that at every developmental stage there are about $30 \%$ students who do not know any word syntax at all. Among those who do know the word syntax to some extent, only a small proportion of them can provide three structures $(7.6 \%$ for freshmen, $6 \%$ for sophomores and $11.1 \%$ for juniors and seniors).

Question 7 is also to test word syntax, using the word "rob". Just as the word "save", more than $35 \%$ of the students did not give any syntactic structure of $r o b$. Only $22 \%$ can provide some structures of $r o b$. Among those who know the structure of rob, about one third can give only one structure and one example. Those who can write down three structures and three examples accounts for only a small proportion, $5.9 \%$ and $3.4 \%$ respectively for the freshmen, $12 \%$ and $5 \%$ for the sophomores, and $13.3 \%$ and $6.7 \%$ for the juniors and seniors. A further examination confirms the developmental feature found with save. As the students' language proficiency level increases, so do the number of word structures stored in their mental lexicon and the number of examples that can be produced by using the stored word structures.

Question 9 asks the students to recognize and correct incorrect word morphology or mistakes. The purpose of this question is to study word morphology in Chinese EFL learners' English mental lexicon. In learning a word, Chinese EFL learners have to know how the word behaves morphologically so that they can recognize and use its different forms. The morphology of a word covers a variety of aspects, singular forms, plural forms, past 
participle forms, present participle forms, and past tense forms, to list just a few. In this question, the five items in the question represent five aspects of word morphology: the plural form, the past tense form, the -ing adjective form, the comparative degree form and the -ed adjective form. All the test words are high frequency words. The students have already learnt the words in junior and senior high schools and pre-test interviews with some students confirm the belief that students are very familiar with these words. Here are the five sentences where the underlined words are supposed to be recognized and corrected: (1) I want to know the detail of the plan. (2) She lift her head. (3) After the shower, the air was nice and cooling. (4) There are few people living here than there used to be. (5) It is more hygienic to drink boiling water.

The collected data show that the students demonstrate very poor performance. A large number of students have difficulty in pointing out the incorrect word morphology and providing correction.

In question 8, students are asked to supply proper English words for the Chinese translation equivalents in specific given contexts. The purpose of the question is to detect Chinese EFL learners' knowledge of word context. When learning a word, Chinese EFL learners have to know how its meaning shifts in different contexts. Through interviews with Chinese English learners and observation in English classes, we learned that most Chinese students can figure out the meaning of English words in a given context, but when they are asked to produce a proper English word for a given Chinese context, they often fail to perform in an expected way.

Question 10 is similar to Question 8 except that the target words are underlined in the sentences and have to be recognized in different contexts, rather than provide correct words in a given context. As far as word meaning recognition is concerned, the majority of students (more than 90\%) can recognize the meaning of words in given contexts, among whom only less than one fourth are able to figure out the right meaning of a word in different contexts. In this test, there is no much difference between performances of students at different developmental stages. A careful examination of the students' responses reveals that they have already learnt the words and they know one Chinese equivalent of each word. However, when a different equivalent other than the one they have already known is required, they have difficulty in giving the right response. It seems that word meaning stored in Chinese EFL learners' English mental lexicon is mechanical: one English word is usually paired with one Chinese meaning, and when a context requires a meaning different from the Chinese one they know, that poses particular difficulties for them.

Compared with word meaning recognition in specific contexts, word production in a given context poses a more serious problem for Chinese EFL learners. A large number of subjects (about 50\%) are not able to produce the right word when a specific context is given. Among those who are, more than $50 \%$ can just provide one correct response out of three. It seems that it is easy for students to recognize the right meaning of a word in a given context, but far more difficult for them to produce the right word in a given context. This part of the test also indicates that juniors and seniors perform better than sophomores, and sophomores better than freshmen, which further confirms the development of word information in Chinese EFL learners' mental lexicon.

Question 11 is to investigate word use in social contexts. There are six sentences in this question. The subjects have to decide whether each sentence is formal or informal and then choose the right word or phrase to complete the sentence. The six sentences are carefully designed to make sure that it is not too difficult for students to finish the task and if there are words or phrases they may not know, Chinese definitions are given.

Only a small number of the students are able to tell whether a sentence is formal or not and provide appropriate choices. Most students can make 3 to 4 right choices. In the interview conducted after the tests, the students admitted that it poses a difficulty for them to decide whether a sentence is formal or informal and then choose the right words. Some even admitted that they had no idea how to decide whether a sentence is formal or informal. In their daily speaking or writing activities, they do not realize that social context determines the choice of words. What they usually do is to find an English word according to the ideas and thoughts in their mind. As the English words stored in their mental lexicon carry no context information but the Chinese meaning, in most cases, the English words that they choose to express their ideas and thoughts may not necessarily be the most appropriate ones.

\section{Conclusion}

Data obtained from the word knowledge test reveal that:

(1) Chinese EFL learners display a very weak acquisition of word knowledge in their English mental lexicon. Of the eight aspects of word knowledge in the mental lexicon, the ones that are stored in the mental lexicon of Chinese EFL learners are word form (phonological form and written form) and word meaning. However, not all word forms stored in their mental lexicon are correct. For quite a number of words, the phonological forms are 
lost in the mental lexicon, and the meanings stored are just L1 equivalent translation. Other aspects of word knowledge are almost absent. Little knowledge of word morphology, word collocation, word syntax, word context and word use in social context is stored in Chinese EFL learners' English mental lexicon.

(2) As the language proficiency level of Chinese EFL learners improves, knowledge of different aspects of word knowledge also increases. To be more specific, knowledge of word form, word meaning, word collocation, word syntax and word context increases as the learners' English language proficiency levels improve. However, there is no dramatic improvement in knowledge of word morphology and word use in social context. Despite the increase in word knowledge, the knowledge stored in Chinese EFL learners' English mental lexicon is still rather limited and even advanced Chinese EFL learners have a high proportion of English words paired with Chinese meaning.

With regard to current EFL vocabulary teaching practice, the following pedagogical suggestions are proposed:

(1) In teaching a word, EFL teachers have to teach not only word form and word meaning, but also other aspects of word knowledge, for example, word collocation, word syntax, word context, word morphology and word use in social contexts, so that students may have a good command of English vocabulary and use it appropriately in different situations.

(2) As knowledge of word forms, word meanings and word use is built up from frequent experience with different kinds of usage events, EFL teachers should provide the students with enough contextualized L2 input, for example, an English class without Chinese, so that students may get to know more usage events about the English vocabulary.

(3) In vocabulary teaching, different words require different teaching strategies. For those words that carry similar lexical concepts across English and Chinese, more opportunities should be provided for students to get familiar with different kinds of usage events and then practice using the word. For those words that do not have a corresponding concept in Chinese, it is quite necessary to help students form a new concept for that word. For those words that carry different lexical concepts across the languages, differences between the lexical concepts should be explained in detail. Core vocabulary that carries different concepts across different languages should be the focus of vocabulary teaching.

\section{References}

Faerch, C., \& Kasper, G. (1986). The role of comprehension in second language learning. Applied Linguistics, (7), 258-274.

Laufer, B. (1990). Ease and difficulty in vocabulary learning: Some teaching implications. Foreign Language Annuals, 23, 147-156. http://dx.doi.org/10.1111/j.1944-9720.1990.tb00355.x

Laufer, B. (2002). What's in a word that makes it hard or easy: Some intralexical factors that affect the learning of words. In N. Schmitt, \& M. J. McCarthy (Eds.), Vocabulary: Description, Acquisition and Pedagogy (pp. 140-155). Shanghai: Shanghai Foreign Language Education Press.

Ma, Guanghui. (2002). A study on the college english vocabulary proficiency of Chinese tertiary-level students. Foreign Language Education, (2), 48-52.

McCarthy, M. J. (1990). Vocabulary. Oxford: Oxford University Press.

Nation, I. S. P. (1990). Teaching and Learning Vocabulary. Boston, MA: Heinle \& Heinle Publisher.

Nation, I. S. P. (2001). Learning Vocabulary in Another Language. Cambridge: Cambridge University Press. http://dx.doi.org/10.1017/CBO9781139524759

Navracsics, J. (2007). Word classes and the bilingual mental lexicon. In Z. Lengyel, \& J. Navracsics (Eds.), Second Language Lexical Progress: Applied Linguistic and Psycholinguistic Perspectives (pp. 17-39). Clevedon: Multilingual Matters.

Richards, J. (1976). The role of vocabulary teaching. TESOL Quarterly, 10(1), 77-89. http://dx.doi.org/10.2307/3585941

Singleton, D. (2000). Language and the Lexicon: An Introduction. London: Arnold \& New York: Oxford University Press Inc.

Zhang, Ping. (2009). Word Association Patterns in Chinese EFL Learners' Mental Lexicon. Nanjing: Southeast University Press.

Zhang, Shanshan. (2006). Exploring the English L2 mental lexicon via word associations. Modern Foreign 
Languages, (2), 164-171.

Zhang, Shujing. (2004). The CLE Mental Lexicon: Nature and Developmental Pattern. Kaifeng: Henan University Press.

\section{Authors}

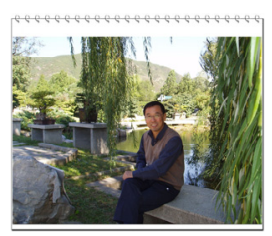

Zhongxin Dai was born in Hebei Province, China, in 1959. He received his B.A. in 1986, M.A. in English language and literature in 1989, and Ph.D. in Education in 2004, all from Beijing Normal (Teachers) University. He was a visiting scholar at Peking University from 1995 to 1996, and at Exeter University from 1999 to 2000.

He is currently a professor in the School of Foreign Languages, North China Electric Power University, Beijing, China. His research interests include second language acquisition, English learning and teaching, and cognitive linguistics.

Kemin Wang is a postgraduate student in the School of Foreign Languages, North China Electric Power University. Her area of research is foreign language teaching and learning. 